Abstracta Iranica Abstracta Iranica

Revue bibliographique pour le domaine irano-aryen

Volume 40-41 | 2019

Comptes rendus des publications de 2017-2018

\title{
Angelika Berlejung \& Judith E. Filitz (eds.). The Physicality of the Other. Masks from the Ancient Near East and the Eastern Mediterranean
}

\section{Astrid Nunn}

\author{
(2) OpenEdition \\ Journals \\ Édition électronique \\ URL : http://journals.openedition.org/abstractairanica/48594 \\ DOI : 10.4000/abstractairanica.48594 \\ ISBN : 1961-960X \\ ISSN : 1961-960X \\ Éditeur : \\ CNRS (UMR 7528 Mondes iraniens et indiens), Éditions de l'IFRI
}

\section{Référence électronique}

Astrid Nunn, « Angelika Berlejung \& Judith E. Filitz (eds.). The Physicality of the Other. Masks from the Ancient Near East and the Eastern Mediterranean », Abstracta Iranica [En ligne], Volume 40-41 | 2019, document 9, mis en ligne le 30 octobre 2019, consulté le 22 avril 2021. URL : http://

journals.openedition.org/abstractairanica/48594; DOI : https://doi.org/10.4000/abstractairanica. 48594

Ce document a été généré automatiquement le 22 avril 2021.

Tous droits réservés 


\title{
Angelika Berlejung \& Judith E. Filitz (eds.). The Physicality of the Other. Masks from the Ancient Near East and the Eastern Mediterranean
}

\author{
Astrid Nunn
}

\section{RÉFÉRENCE}

Angelika Berlejung \& Judith E. Filitz (eds.). The Physicality of the Other. Masks from the Ancient Near East and the Eastern Mediterranean. Tübingen: Mohr Siebeck, 2018, X-570 p. (Orientalische Religionen in der Antike 27)

1 Cette monographie traite du thème passionnant du masque. Ce genre d'artéfact apparait au Levant dès le néolithique et accompagne les cultures antiques (et modernes) dans les domaines très divers que sont le rituel religieux, le théâtre et les arts. Elle est le résultat d'un symposium international qui eut lieu à Leipzig en novembre 2015. Des scientifiques d'horizons divers ont présenté les masques en Égypte (Renée F. Friedman, Alexandra von Lieven, Asja Müller) en Israël/Palestine (Izak Cornelius, Itzhaq Shai), Syrie (Juliane Stein), Phénicie (Adriano Orsingher), Mésopotamie (Claudia Beuger, Takayoshi Oshima), Chypre (Erin Walcek Averett), la Grèce (Angeliki Varakis) et la culture étrusque et latine (Daniel Dost) sur un laps de temps du IXème millénaire jusqu'à l'époque romaine.

2 L'introduction de Judith E. Filitz, Of Masks and Men. Thoughts on Masks from Different Perspectives, élucide d'emblée l'état d'esprit de cette rencontre: traiter du "phénomène masque» sous toutes ses facettes, qu'elles soient archéologiques, iconographiques, anthropologiques et philologico-théologiques (Angelika Berlejung, Claudia Beuger, Takayoshi Oshima). Selon la culture et la période prévalent l'aspect 
religieux lié aux ancêtres, aux esprits et aux dieux - au néolithique -, à la vie et à la mort - en Égypte - ou au visible et au caché - en Grèce.

Quel que soit son usage, le masque est toujours un moyen de communication entre deux mondes - indissociables - , l'un humain et vivant, l'autre supranaturel ou simplement désirable. La contribution d'Alfred Schäfer (Zwischenwelten. Maskenauftritte im Egungu/Kutito-Geheimbund), nous sensibilise par la description d'une fête africaine moderne.

4 Deux contributions sont à retenir dans le cadre des Abstracta Iranica.

5 Ephraim Stern: Iron Age-Persian Masks and Protomes from Tel Dor, 169-189, offre un catalogue des nombreux petits masques et protomés en terre trouvés à Tel Dor. Il reprend sa classification, déjà exposée à plusieurs reprises, en deux catégories : réaliste et grotesque. Selon l'A. les faces réalistes représentent vraisemblablement des divinités, les autres des « evil spirits ». Cet article est une synthèse utile.

6 Plus intéressante est la compilation présentée comme annexe à la fin de la monographie : Angelika Berlejung unter Mitarbeit von Susanne Kohlhaas und Juliane Stein: Katalog der anthropomorphen Masken der südlichen Levante vom präkeramischen Neolithikum B bis zum Beginn der hellenistischen Zeit (9. Jt. - 4. Jh. V. Chr.), 397-550.

7104 pièces sont présentées dans l'ordre chronologique. Les numéros 65 à 101 sont d'époque achéménide. Le territoire considéré couvre Israël, la Jordanie et le Liban. Les masques ont tous déjà été publiés, la plupart toutefois dans des publications peu accessibles. Les A. ont essayé d'obtenir de bonnes photos. Bien que cette annexe ne soit pas accompagnée de texte explicatif, le lecteur peut s'informer sur la signification des masques illustrés dans les différents articles.

\section{AUTEURS}

\section{ASTRID NUNN}

Université de Munich 